\title{
Compulsory Mental Health Treatment in Hong Kong: Which Way Forward?
}

\author{
D Cheung
}

\begin{abstract}
On 25 to 26 August 2017, the 'Compulsory Mental Health Treatment in Hong Kong: Which Way Forward?' conference was held in Hong Kong. Academics and practitioners from the United Kingdom, United States, New Zealand, and Hong Kong came together to discuss such important topics as the philosophical justifications for compulsory treatment, constitutional and human rights, and how compulsory powers are and should be used in practice. Speakers and conference participants then engaged in roundtable discussions on various issues that arose, in particular how reform of the law regulating compulsory mental health treatment in Hong Kong should proceed.
\end{abstract}

Key words: Hong Kong; Human rights; Involuntary treatment, psychiatric; Mental health

Daisy Cheung, Assistant Professor, Faculty of Law, University of Hong Kong, Hong Kong

Address for correspondence: Ms Daisy Cheung, 4.06 Cheng Yu Tung Building, Centennial Campus, University of Hong Kong, Pokfulam, Hong Kong. Email: dtcheung@hku.hk

Submitted: 28 February 2018; Accepted: 1 June 2018

\section{Introduction}

On 25 to 26 August 2017, the Centre for Medical Ethics and Law of the University of Hong Kong, in collaboration with the Centre of Law, Medicine and Life Sciences of the University of Cambridge, Ethox Centre of the University of Oxford, and the Hong Kong College of Psychiatrists hosted the "Compulsory Mental Health Treatment in Hong Kong: Which Way Forward?' conference to discuss the present status of compulsory mental health treatment in Hong Kong and the way forward.

The conference organisers first saw the need for a conference on this topic because of the minimal writing and discussion on it, particularly from a legal point of view. This is despite the fact that fundamental human rights are engaged in the compulsory admission and treatment process. It was their view that an event where they could bring together the different stakeholders in mental health, as well as international academics and professionals, would be a good forum to discuss some of these highly important issues and to fill in some of the gaps.

The aims of this conference included, at a minimum, more awareness about the legal issues facing compulsory mental health treatment in Hong Kong. Because of the relative lack of writing on this topic, it has not received sufficient attention and has consequently failed to gain sufficient impetus for legal reform. With more awareness, the conference organisers hoped that the conference would also serve to garner support for change, as well as result in proposals for viable pathways for reform in Hong Kong. This report summarises what was discussed at the conference.

\section{Report}

The conference spanned two days, covering issues from a theoretical perspective on the first day and issues from a practical perspective on the second.

\section{Theoretical perspectives}

Professor John McMillan from the University of Otago began the conference with a presentation looking at compulsory mental health treatment from a philosophical perspective, entitled 'Key ethical concepts in the justification of compulsory detention and treatment'. He provided a framework of six ethical concepts: (1) maximise liberty, (2) first of all, do no harm, (3) nurture autonomy and recovery, (4) prevent harm to self, (5) prevent harm to others, and (6) consistency and fairness. Using several case studies, he explored the content of each of these ethical concepts, and how they manifested in several pieces of mental health legislation. In doing so, he raised a number of key questions. For example, in the context of prevention of harm to self, McMillan highlighted the need to strike an appropriate balance between the involuntariness of the individual's behaviour and the probability of improving the individual's autonomy and well-being (factoring in the harms associated with coercion and compulsion). These key concepts provided an ethical foundation upon which the rest of the discussions throughout the conference were based.

The next section of the conference was on the United Nation Convention on the Rights of Persons with Disabilities (UNCRPD). Professor Peter Bartlett from the University of Nottingham gave a presentation on 'The UNCRPD and Mental Health Law', where he introduced the philosophy 
behind the UNCRPD, as well as the key articles that protect the rights of individuals with mental impairments and what these articles mean for mental health legislation. In particular, he focused on Article 12 (which has implications for mental capacity law), Articles 17 and 25 (which have implications for compulsory treatment laws), and Article 14 (which has guidance from the Committee on the Rights of Persons with Disabilities stating that compulsory detention on the basis of actual or perceived impairments should be abolished). The key take-home message was that, because the current view of mental health law is mired in a vision where compulsion is the core, it is difficult to see how the goals of the UNCRPD can truly be achieved.

Professor Carole Petersen from the University of Hawaii followed with a presentation entitled 'Unfinished Business: Reforming Hong Kong's Mental Health Ordinance to Comply with International Norms'. She discussed the background of Hong Kong's Mental Health Ordinance, including reasons why Hong Kong has not yet reformed the Ordinance. She then discussed the articles in the UNCRPD that are particularly relevant to individuals with mental impairments, and what implications these articles may have for mental health legislation in Hong Kong. In particular, she provided examples from the Mental Health Ordinance that demonstrate the need for reform. For example, she pointed out that even the stated purpose of the Mental Health Ordinance contains objectionable terminology which violates the letter and spirit of the UNCRPD.

The last section of the first day was on specific issues arising from mental health legislation in Hong Kong and other jurisdictions. Professor John Dawson from the University of Otago began with a presentation entitled 'Mental Health Acts in the Commonwealth: Criteria and Powers'. He explored the usual contents of mental health acts in the Commonwealth, including some of the common characteristics they share and issues of continuing controversy. For example, in relation to standards for compulsion, the common elements include: (1) severe 'mental disorder' or 'mental illness', (2) danger to self or others, or gravely disabled, (3) no less restrictive alternative, and sometimes (4) lack of capacity to refuse psychiatric treatment. Continuing controversies in this area include whether 'mental disorder' or 'mental illness' should be defined more fully, and whether an incapacity requirement should be included.

Ms Daisy Cheung from the University of Hong Kong then gave a presentation entitled 'The Compulsory Psychiatric Regime in Hong Kong: Constitutional Perspectives', in which she discussed several problematic areas with the civil compulsory admission and treatment regime in Hong Kong. Apart from the lack of safeguards in relation to treatment and duration of stay, she argued that the provision for long-term detention in the Mental Health Ordinance was unconstitutional due to the restricted role of the District Judge in the process. In light of this, she put forward two types of solutions to rectify the situation, quick-fix solutions and an overhaul of the regime.

At the end of the first day, the speakers engaged in a roundtable discussion with each other and members of the audience, which included psychiatrists, family medicine practitioners, clinical psychologists, social workers, members of the Equal Opportunities Commission, lawyers, mental health service users and representatives from mental health advocacy groups, students, and faculty members of the University of Hong Kong. Themes that emerged from the discussion included UNCRPD and rights-based principles and competing concerns that may arise, as well as the importance of safeguards such as review mechanisms and independent advocacy services (including the importance of educating patients about their rights). The possibility of a voluntary Code of Practice or a Patients' Bill of Rights was suggested, given that discussions with practitioners indicated that rights seemed to be better protected in practice.

\section{Practical Perspectives}

Judge Mark Hinchliffe, Deputy Chamber President of the First-tier Tribunal (Health Education and Social Care Chamber), began the second day of the conference with the keynote speech entitled 'Compulsory Mental Health Treatment: When Should Judges Get Involved?'. He discussed the role of the First-tier Tribunal in the compulsory detention and treatment process in the United Kingdom, covering various areas such as the key stages in the development of the current system of tribunals (eg, the transition from a primarily inquisitorial to an adversarial model, which he argued helped to clarify issues and allowed for a greater focus on due process safeguards), differences between the United Kingdom and Hong Kong models, what the First-tier Tribunal does when it considers a case and how it might be possible to further refine judicial involvement in the future (eg, the possible inclusion of an incapacity requirement in the compulsion criteria to achieve better parity with how physical health problems are managed). Judge Hinchliffe's speech was the subject of an article in The Telegraph (available from: http://www.telegraph.co.uk/ news/2017/08/29/mental-health-patients-should-haverights-refuse-treatment-senior/).

The next section of the conference was on compulsory powers in the hospital setting. Dr Elizabeth Fistein of the University of Cambridge began with her presentation entitled 'Compulsory Admission in England \& Wales Use of the Mental Health Act 1983 as Amended 2007'. She discussed her empirical research on how practitioners decided whether compulsory detention is appropriate, and what factors they thought were most relevant. In particular, she focused on the practical considerations practitioners took into account in the areas of diagnosis, decision-making capacity, necessity of detention, risk and availability of treatment, with qualitative data from the practitioners about previous cases they had dealt with. Fistein then gave suggestions for practitioners, as well as proposals for future legislation. 
Dr Bonnie Siu of Castle Peak Hospital then gave a presentation entitled 'Compulsory admission in Hong Kong: the balance between paternalism and patient liberty?', where she gave a comprehensive overview of the various laws (both in the civil and criminal context) governing compulsory detention and treatment in Hong Kong, as well as statistics from Castle Peak Hospital regarding voluntary and compulsory admissions, diagnoses of active inpatients from compulsory admissions, and reasons for detention.

The following section of the conference explored the use of compulsory powers in the community setting. Dr Michael Dunn of the University of Oxford began with a presentation entitled 'The use of Community Treatment Orders in England: Ethically justifiable?', where he introduced the Community Treatment Order and discussed the evidence regarding its efficacy, in particular in relation to its ability to reduce readmission rates. He then presented his empirical research on whether Community Treatment Orders were ethically justifiable, using qualitative data from patients, psychiatrists and family carers. Dunn then provided some reflection on the justifications for using Community Treatment Orders and whether attention might better be focused on promoting patient autonomy in other ways.

Dr Eric Cheung (formerly of Castle Peak Hospital) gave the last presentation of the conference, entitled 'Compulsory psychiatric treatment in the community in Hong Kong', where he introduced the types of compulsory treatment in the community in Hong Kong. He focused on the conditional discharge order, providing historical context (eg, the impetus behind the creation of this order in the 1980s) and a description of its key features. He then presented some local research and statistics regarding the order and ended with recommendations for compulsory community treatment in Hong Kong going forward.

The end of the conference took the form of another roundtable discussion with the speakers of the second day and members of the audience. This roundtable discussion brought together the themes that came out of the presentations from both days and focused on suggestions and recommendations for reform in Hong Kong. In particular, a framework created by Fistein and her collaborators was used to guide the discussion. The framework had five axes: (1) diagnosis, (2) therapeutic aim, (3) risk, (4) capacity and (5) review process. The discussion revolved around the questions of what level of each axis would be appropriate for the Hong Kong context and what the relevant concerns might be. The speakers and members of the audience also discussed next steps for reform, including reform of the conditional discharge order and the likelihood of support for the voluntary Code of Practice. These suggestions will have implications for mental health law reform in Hong Kong, in particular in relation to determining the most appropriate strategy for reform given the local context of Hong Kong and its international commitments under various international treaties.

This conference is one of the very few in Hong Kong that have been organised on the important topic of compulsory mental health treatment. It offered an excellent opportunity to bring together academics and professionals in related fields for a much-needed discussion on the need and directions for reform. The interdisciplinary mix of the audience created a synergistic effect that gave rise to new and insightful perspectives. It is hoped that this conference will lead to further discussions about implementing mental health law reform in Hong Kong in the near future.

\section{Acknowledgements}

The author would like to thank the collaborators of this conference: the Centre for Law, Medicine and Life Sciences at the University of Cambridge, the Ethox Centre at the University of Oxford, and the Hong Kong College of Psychiatrists. The author is immensely grateful for the support and guidance of Dr Elizabeth Fistein and Dr Michael Dunn, without whom this conference would not have been possible. 